\title{
Design and Development of a Narrative-based Tabletop Game for Promoting Soft Skills Acquisition in Technical Students in The South African Context
}

\author{
Lance R. Bunt \\ School of Information Technology, Faculty of Natural and \\ Agricultural SciencesNorth-West University Vanderbijlpark, \\ South Africa \\ Lance.Bunt@nwu.ac.za \\ Jacob J. Greeff \\ School of Information Technology, Faculty of Natural and \\ Agricultural Sciences \\ North-West University Vanderbijlpark, South Africa \\ Japie.Greeff@nwu.ac.za
}

\begin{abstract}
A serious tabletop game called "Gr8 Success!" has been developed for an undergraduate Communication skills module at the North-West University (NWU) in South Africa. This paper presents the details of the development process and discusses the first play tested prototype of the serious game in question. The game is described in the context of a conceptual framework being developed by researchers at the Serious Game Institute of South Africa (SGI-SA).
\end{abstract} design

Keywords-serious games, soft skills, tabletop games, game

\section{INTRODUCTION}

In the current marketplace it is not unfair to say that communication skills have become the differentiator between good and mediocre work candidates. This can clearly be seen in the report provided by tech giants Google after studying their own hiring, promotion and firing practice and discovering that soft skills (communicating well with others, having empathy, problem solving, etc.) were the most valuable factors in predicting success in their company [1]. This study, reported by the Washington Post in 2017, refutes the popular belief that hard skills (such as skills accrued in STEM fields) are more crucial for workplace success than transferable [soft] skills. The evidence of a renewed emphasis on non-technical, soft skills in tertiary education graduates also presents itself in the revised North-West University (NWU) Language Policy for Higher Education (HE) draft released in 2018, which states: "There is much concern as to the consultations with and role of professional councils and boards in decisions regarding the communication skills of graduates in qualifications registered with these bodies" [2]. The document goes on to underline this point by expressing the need for "long-term commitment" and "resources" supplied by the NWU to teach these at the HE level [2]. The disciplines being made reference to are almost exclusively made up of highly technical, complex subject fields such as engineering, computer science, business and health sciences.

An opportunity to think outside the box presented itself when the overarching structure of the BSc IT programme at NWU was subject to an alignment process across its three campuses in 2017, necessitating change in terms of addressing the emerging concerns regarding the employability of graduates.
The nascent game presented in this paper-Gr8 Success! - is a narrative-based, multiplayer, tabletop serious game which looks to teach players a wide range of soft skills through implicit learning. It is light on story and world building, as it requires players to use their imagination and various reflective practices to come up with reasons for how and why they play modifier cards on an assortment of characters to show growth throughout the course of the game. The work done in this paper contributes to an ongoing project at NWU to formulate a theoretical framework for the development of serious games as an end-to-end test of the envisioned framework. This particular design framework will be explored further in future research.

\section{Milieu AND RATIONALE}

The Serious games Institute of South Africa (SGI-SA) is a production, research and support unit on the NWU Vaal Campus which endeavors to compliment lecturing staff with serious game solutions that can be incorporated in their lessons and broader teaching and learning practice [3]. There was in the past a greater focus on digital games for learning, but the literature shows an emergent re-evaluation of tabletop games as players yearn for a uniquely social experience [4] [5] [6] [7]. The main advantage of utilising these physical, pervasive interventions is the eye contact and various ancillary social dynamics (interaction, social play, turn-taking, collaboration) involved therein [8]. As the nature of the problem is communicationbased, employing a tabletop game seemed a natural solution for the third year Communication Skills module that forms part of the BSc IT curriculum at NWU.

\section{PROBLEM STATEMENT}

The ITRW 315 Communication skills module is an integral part of the BSc in IT programme at the North-West University. It is accepted that the student has the knowledge, skill, and

maturity that can be expected of a third-year student (in Information Technology). Through suitable material and discussions, an attempt is made to make students aware that they should live and act independently in all walks of life, ranging from their work environment to family life. Attention is, furthermore, paid and assignments issued to prepare documentation in a professional way. The module is a departure from the largely technical content of the course, but arising from sessions with people from industry, it is clear that employers 
expect broader skills and knowledge than merely technical skills and knowledge from their employees.

Therefore, a module that pays attention to interpersonal communication and technical communication is included in the IT programme. This often leads the course to be perceived as trivial "fluff" by those who aim to accrue only technical skills and prowess during their studies. The serious game in question intends to address this and make this perception more positive in viewing the coursework as foundational to both personal and work success, and to attempt to teach communication skills through play rather than a traditional classroom-based approach.

Furthermore, students have expressed a lack of engagement in taking the module. Being required to study this content as a compulsory module, BSc students come to realise they have no autonomy in choosing the material they have to learn in the latter years of their studies. Interestingly, courses at the NWU use Bloom's Taxonomy of Learning Domains to promote higher forms of thinking (cognitive-centered) in its educational practice, but the nature of communication and the study thereof expects a level of affective engagement from its scholars currently missing from the presented structure. Gr8 Success! subsequently aims to inject a level of excitement into the compulsory module to encourage enthusiasm in the BSc student strata and aid them in interrogating and internalising the concepts dealt with in the module.

Few tabletop serious games have surfaced from South African developers to address teaching and learning needs. SGISA sought to add value to this unexplored territory of African, modern, educational games media by developing Gr8Success! as a physical card game with minimal components for optimal setup and play time.

\section{IV.LITERATURE STUDY}

The concept of soft skills has existed in a variety of contexts (for a long time) [9]. Soft skills are considered to be the "cluster of personality traits, social graces, facility with language, personal habits, friendliness and optimism" [10] that have increasingly become sought after in technical professions such as computer science and information technology. There are three [10] major driving factors for these becoming so essential to effective business functioning, including: the need to improve the bottom line; ever more competition between organisations; and globalisation.

In teaching these tacit concepts to students, the researchers believe appealing to self-determination theory (SDT) and implicit learning are the most effective course of action. SDT describes human motivation as being motivated either extrinsically or intrinsically; depending on the social context and classifies rewards for behaving in an autonomous or controlled manner [11]. Implicit knowledge acquisition is regarded as a foundational process which develops "abstract and tacit knowledge of all kinds" [12]. Moreover, researchers have supported the notion that this form of learning allows for more information to be absorbed by the learner [13].

The interplay between these concepts is foundational to $\mathrm{Gr} 8$ Success! and its resulting educational benefits. A player has to be intrinsically motivated and must want to play the game in order to benefit from the latent value of the educational concepts baked into its mechanics and themes. This is not only critical for games with an emphasis on learning, but as pointed out by McGonigal, voluntary participation - along with rules, goals and feedback - are the four main components of a game [14]. This motivation can stem from a variety of sources, including: feeling accomplished during a game; feeling enjoyment; the pursuit of knowledge; curiosity of the topic; effortful thinking; mastery; learning goals; pride; and/or competency. Ryan and Deci [15] succinctly described what it takes for an individual to feel intrinsically motivated to complete a task as the following: That their choice matters in the broader context of the activity; a sense of proficiency-gain is nurtured by the activity; and that they feel a sense of belonging in a community or "greater whole".

The researchers also believe in the advantages afforded by utilising The Taxonomy of Educational Objectives to classify educational goals, objectives and standards [16]; especially when engaging with inherently social coursework such as communication skills. Design philosophies behind the game are based principally on the experience of the two game designers. Additionally, SGI-SA members employed standard best practice techniques defined by game designers throughout the ages, such as simplification, failures as successes, keeping the audience in mind, and paying special attention to the rules players often forget - to name but a few. A future paper will outline the exact serious game design framework used for this and other games designed by SGI-SA.

\section{APPROACH}

The project employs Education Design Research (EDR) as a method to undertake various procedures to: gather information, conceptualise, design, develop and implement Gr8 Success! as a successful serious game project. EDR is relevant for educational practice and policy by its nature, and intends to develop research-based solutions or validate theories about teaching and learning practice [17]. It was chosen as the appropriate methodology as it is conducted in a real-world setting where researchers and practitioners work together to solve research problems within an educational context. This is the same procedure followed in previous SGI-SA projects and encompasses a number of research cycles and data collection strategies: (i) a contextual analysis (literature review, needs analysis, concept design); (ii) prototype design, prototype testing and ancillary data collection; and (iii) evaluatory strategies (final evaluation, communication of findings) [18]. Design research allows for the collecting and analysing of qualitative and quantitative data, and for triangulating the findings [17]. In each cycle of the project SGI-SA makes use

of an adapted SCRUM agile software development cycle [19], as it facilitates feature iteration, allows the project team to deliver refined, tuned and integrated features which can be used to test the quality of the game throughout its development, and permit the team to integrate user feedback as early as possible in the development process. The same EDR process is followed with Gr8 Success!, and this represents the first prototype loop after the initial investigation [18]: 


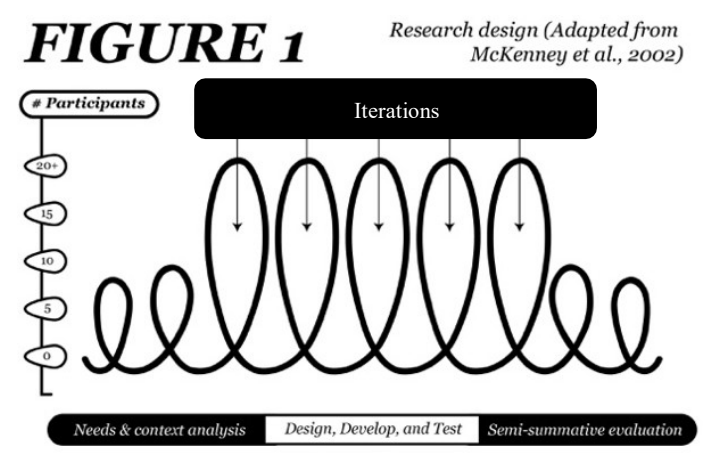

Fig. 1. The design cycles for Gr8 Success!

Figure 1 illustrates the research design cycles followed. This method affords validity to the research and ensures that the results are adequate to inform the researchers after each iteration has been developed. Conducting research in such a setting is challenging and demands meticulous research design. With design research it is therefore fundamental not only to reflect on the cyclical, iterative character of the design of the intervention, but also to ensure that the process is rigorous, relevant and conducted in collaboration with all role players.

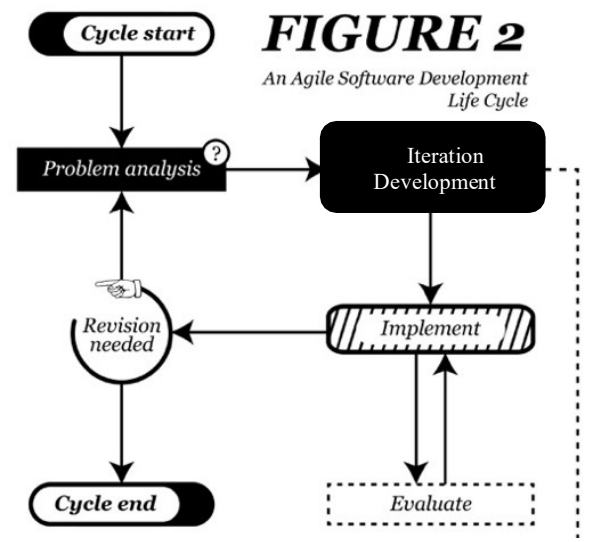

Fig. 2. Design cycle process followed and the Agile Software Development Life Cycle

Figure 2 illustrates the design cycle process and the agile software development life cycle. Each cycle will start with problem analysis before the design, development, and testing. During the design progress of each iteration (cycle) of Gr8 Success!, the researchers will test the latest iteration of the game with chosen participants to give their opinion on the design of various game elements before the next iteration is

developed. These participants will be comprised of a cohort of students on the NWU Vaal Triangle Campus. Additionally, the team will endeavor to collect qualitative and quantitative data for each iteration of the game in order to inform further developments.

\section{DESIGN OF THE GAME}

Gr8 Success! was designed as an entertaining game first and an educational experience second. This approach was taken to ensure a fun play experience which exploits a self- deterministic view of human beings, in which implicit learning takes place. This top-down design (entertainment first) contrasts the typical bottom-up design approach (educational first). Both have merit in different contexts, but in this instance the teams' goal was to focus first on adoption and rather gain buy-in from players before shoehorning educational content into the experience. Moreover, Gr8 Success! was designed as a tabletop game to contrast previous SGI-SA works. SGI-SA decided to venture into uncharted territory by testing the developing conceptual serious game design framework in various contexts and sought to not be restricted by digital design requirements. SGI-SA has been based in the School of Information Technology (now the School of Computer Sciences and Information Systems) for over seven years, leading the team to focus their efforts on digital serious game development.

The two main members of SGI-SA decided to approach the project differently by creating a game in which: (i) they were the content experts and (ii) sole benefactors in terms of the creative process. SGI-SA had largely functioned as a support unit at the North-West University up until this point (2018), aiding lecturers and researchers in creating serious game products to address gaps in teaching and learning practice. The new team decided to undertake a project where they acted as content experts to minimise the typical problems experienced when a wide array of stakeholders are expected to collaborate on a project. This was done to ensure that the framework under development is tested with equal levels of rigor from all sides. Playing the roles of all stakeholders involved in serious game design allows the researchers to glean further insights into the process.

\section{A. Inspiration}

The team at SGI-SA sought to explore themes of "modification" and "growth" with Gr8 Success!. This is reflected in the chosen game elements and mechanics which were inspired by existing, popular games such as Gloom and Fluxx. Gloom sees players modify their chosen family's character cards by placing transparent cards on top of them in order to make them increasingly unhappy (until they eventually die). Similarly, Fluxx's mechanics emerge through play, modifying the game experience realis tempus. Various other sources also had an influence on the aesthetics, mechanics andoverall direction of Gr8 Success!, including:

- Covey's habits of effectiveness [20];

- Thomas Wellmann art;

- Max Fiedler art;

- Jack Teagle art;

- Epic spell wars;

- Dixit; and

- Cards against humanity.

The above-listed sources were pooled and visually represented during the conceptualisation phase of the development process being followed. A moodboard depicting the various inspirations was developed to aid non-designers in 
understanding the rich pool of references used to develop the visual identity and mechanical focus of the game:

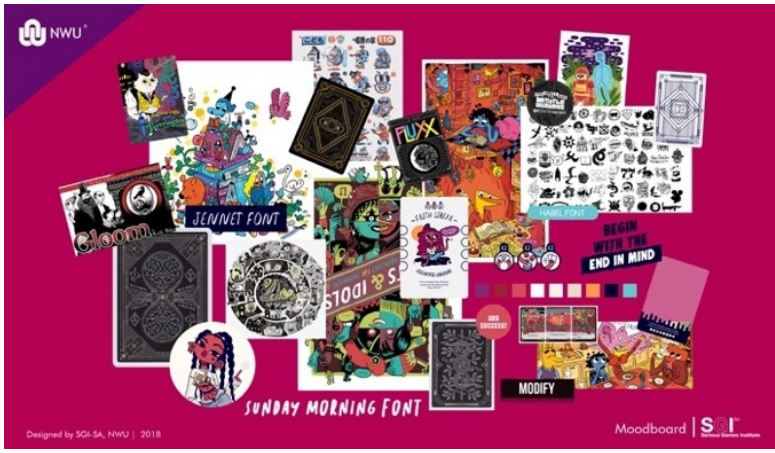

Fig. 3. The moodboard created for Gr8 Success!

\section{B. Character design}

The design of the characters followed an empirical approach with the intention of giving students a voice. Instead of a conventional "serious games" approach, the designers took inspiration from the students in their immediate vicinity. $G r 8$ Success! takes place at a fictional South African tertiary education institution, similar to the North-West University Vaal Campus. Deliberately, not much world building has been done in order to afford players the opportunity to conjure up their own ideas for what this environment looks and feels like.

Players may choose from one of eight possible player characters for a single game of Gr8 Success!. Players take control of exaggerated versions of tertiary education students (in the form of character cards) and modify the core components of their behaviour and soft skill-related characteristics by placing modifier cards on top of these characters.

\section{Iconography}

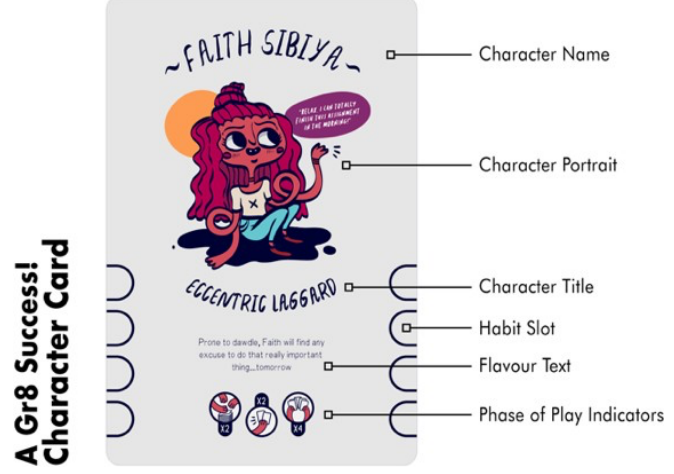

Fig. 4. The anatomy of a Gr8 Success! character card

The first piece of information that can be found on a $G r 8$ Success! character card is the character's name. This is unique to each of the eight characters found in the base game and does not change when a modifier card is placed on top of it. An illustration of the character can be found beneath their name and is the second item which remains unaffected by modifiers. Below the visual depiction of the character is their title - a description of their current behaviour, traits, or circumstance. The flavour text appears under the title and simply adds additional background information about the modifier card. Eight significant elements can be found on either side of the character card and are called habit slots. Rather than pointing to the habits outright, the slots are left blank to allow players to explore other concepts should they feel they are more applicable. Positive and negative values are applied through modifier cards, but the actual value they represent in the game world is conveyed through the emergent narrative. Placing the transparent modifier cards over the character cards fills these open slots.

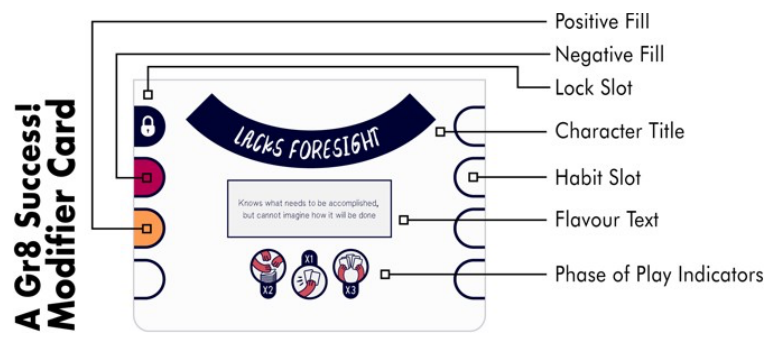

Fig. 5. The anatomy of a Gr8 Success! modifier card

A modifier card mimics the bottom half of a character card, and has the following uniform features: (i) $1 \mathrm{x}$ Character title;

(ii) $8 x$ Habit slots; (iii) Flavour text; and (iv) Phase of play indicators. What is different, however, are the coloured fills and locks which cover the open slots on the bottom card. Orange and pink fills represent positive values for the former and negative values for the latter. These orange and pink fills can cover one another without violating the rules, but locks behave differently. A lock cannot be covered by a modifier that has a coloured fill taking up the same slot position. Cards with lock slots can only be removed by a player expending a single action point to move them to the discard pile.

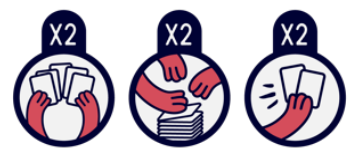

Fig. 6. The phases of play visually represented in Gr8 Success!

The above icons represent the phases of play in Gr8 Success!. Each symbol is made up of a value indicating the number of cards to draw (left icon), suitable actions to take (middle icon) and value to have in hand (right icon), per turn. The base value of each is unique for the eight playable characters and are modified through play as the game progresses. These mechanics are inspired by the gameplay in the popular card game-Fluxx - which can be described as having emergent mechanics. The rules of Fluxx are determined 
as the game is played, altering the number of cards drawn from the game deck and how many cards a player is allowed to hold in their hand at the end of their turn.

\section{Mechanics}

The main aim of the game is to fill the eight spheres (slots) of life and work effectiveness depicted on the face of a $\mathrm{Gr} 8$ Success! character card. These slots are filled by playing the modifier cards discussed in VI (C.) and then narratively describing what has changed in the character's life to have the specified impact. Through describing positive and negative actions or events in the characters' lives, the unfolding story progresses from player to player. All of this is achieved by placing translucent modifier cards on top of a character. These cards are made up of positive and negative habit slot fills and is ultimately designed to be a simple but spirited experience.

The object of the game is to increase the efficacy of the player's character with modifier cards that cause positive (and sometimes negative) effects and reinforce constructive, effective behaviour. Players eventually lead characters to become well-rounded individuals by appealing to the eight habits (as put forward by S. Covey) —which initially appear blank on player cards [20]. Concurrently, negative modifiers are presented to opponent's characters, affecting their overall final score.

We will now provide a spotlight on each of the pertinent mechanical features in Gr8 Success! and explain their impact on the game and the ensuing learning experience:

\section{1) Changing your abilities}

The theme of "growth" is represented by the ability of the player to directly change a characters abilities (phases of play icons) by placing a modifier card on top of them.

\section{2) Variable hand size, draw and play}

The game mechanics themselves are adapted through play_placing modifier cards on your own or another players character card.

\section{3) Narrative-focused story telling}

The only other prerequisite to play a modifier card than the number of actions indicated on the active players character card is the narrative statement a player makes to explain how the character gets from point A to point B. There needs to be a logical reason for the specific modification (story event) to takeplace.

\section{4) Emergent storytelling}

Players do not only modify the characteristics, abilities and stories of their own characters, but the aspects of other player characters as well. This lends the game an emergent feel, as players are expected to deal with a wide variety of possibilities if another player modifies their character in a particular way.

\section{5) Summary storytelling}

On completing a game of Gr8 Success!-when all characters have fulfilled the slots on the face of their character card-each player is asked to provide a synopsis of their characters journey in the game through reflective practice.

\section{6) Competitive gameplay}

Unlike many other serious games, the creators of Gr8 Success! wanted it to be competitive in nature. Players are, in essence, vying to see who can "create" the most effective character, subverting a variety of retrograde mechanical constraints from previous games.

\section{7) Strategic depth}

Players are encouraged to make deliberate, calculated modifier card plays on theirs and their opponents' characters. The designers have tried to strike a balance between complexity and decision-making to heighten the level of depth.

\section{8) Alliance forming and backstabbing}

Social relational aspects such as collaboration, betrayal, cooperation and revenge are all represented in game through the interplay of modifier cards and player choices.

\section{9) Powerful card combinations}

It is just as possible for players to complete a game with only positive modifiers on their character as it is for their character to be exclusively negative. Players are encouraged to learn the associations between the phase-of-play modifiers and the correlating slot-fillers on modification cards to maximise their strategic possibilities and game impact.

\section{0) Implicit learning}

The team at SGI-SA has expressed interest in exploring the phenomenon of acquiring knowledge independently of "conscious attempts to do so" [12]. Gr8 Success! has thus been designed to allow players to learn without full awareness of doing so. The mechanism for achieving this is by having players indirectly work with the subject material without ever coming into contact with it overtly.

\section{1) Scoring}

A player does not need to fill each slot on their character card first in order to be victorious in a game of Gr8 Success!. A method for scoring has been introduced to the game to allow for greater levels of variety and chance:

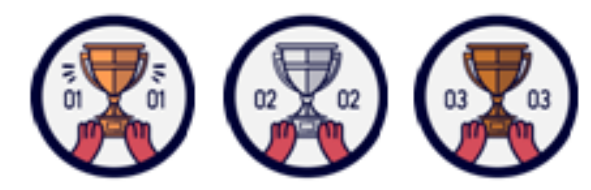

Fig. 7. Placement tokens indicating the position a player of Gr8 Success! finishes the game in.

The above tokens represent the placement of the player at the end of a game. This position is indicated by the number printed on the face of the token. These values are tied to the final score a player achieves after filling every habit slot on their character card. For example, in a three player game the player to self-actualise (fill every slot on their character card) first is awarded three (3) points, the second player to fill all of their slots gets two (2), while the final player gets one (1). The number of points from each individual slot is then added to or subtracted from this self-actualisation value. 


\section{E. Playtesting}

As an EDR approach is followed, the researchers have used numerous opportunities to playtest the game with various players, both inside and outside of the target demographic for the final intervention. Although the researchers do agree with the notion presented in the literature of the serious game being designed being part of a participatory design process, by following a top-down approach the researchers wished to create a game that would be fun for anyone, and not just a narrow, predefined demographic (i.e. university students).

As such, players in the four main playtesting events were made up of children 8 years and older, university students, fellow lecturers, external participants (family, friends) and older players to see the results from different play experiences. Based on the overwhelming positivity received from participants thus far, the researchers have decided to test future prototypes with SIMS and IMI to get a more scientific measure of impact. The results of these tests will be explored in a future paper.

\section{F. Establishing motivation}

Communication skills students were informally and anonymously polled in February 2018 to gauge whether or not they would want a serious game to be developed to aid them in learning the content of the module. Of the respondents $(\mathrm{N}=33)$, the majority were in favour (88\%) of having a serious game for the course.

TABLE I. SERIOUS GAME QUESTION POLL RESULTS

\begin{tabular}{|l|l|l|}
\hline \multicolumn{3}{|c|}{$\begin{array}{c}\text { Would you like a game to help you learn the content of this } \\
\text { Communication Skills module? }\end{array}$} \\
\hline \multicolumn{1}{|c|}{ Response item } & Votes & Percentage (\%) \\
\hline Yes, please & 29 & 88 \\
\hline No, thank you & 2 & 6 \\
\hline Unsure & 2 & 6 \\
\hline
\end{tabular}

This means that a mere $26.6 \%$ of the target population answered the question, but it is important to keep in mind the timeframe of the probe and the prompts to complete it. February is the beginning of the first academic semester at NWU, resulting in many students possibly overlooking a week-long poll on their LMS. Moreover, many students were not yet added to the subject site on the campus-wide LMS, eFundi. Given a final class size of 124, and a three option scale, a $95 \%$ confidence level would be achieved with $\mathrm{N}=33$ with a confidence interval of $\approx 15 \%$. Given three available choice options with a width of $33 \%$ each the researchers found this to mean that the class was overwhelmingly interested.

\section{RESULTS}

A small number of sampled students were given the opportunity to provide feedback via a Google Survey on the game prototype and $83 \%$ agreed with the statement that Gr8 Success! "seems easy to learn". Such a positive perception means that the game appears to be accessible and straightforward for potential players. The remaining $17 \%$ of responses were neutral regarding the prompt, indicating a level of hesitance by a narrow number of participants in terms of learning to play the game itself.

Interestingly, the majority of responses $(67 \%)$ recorded neutral feelings towards the statement that Gr8 Success! has "minimal" rules. Considering this result with the first in mind, it would appear that respondents still perceive the game as approachable and simple to learn despite the anticipated number of rules.

Half $(50 \%)$ of these responses agreed that the game seems relatively complex; while a smaller $33 \%$ believed it was not. "Complexity", in this instance, refers to the perceived number of moving parts in the game and their relative intricacy in understanding the underlying game design and mechanics. Curiously, the foreseen complexity did not influence the participants' belief that Gr8 Success! is easy to learn.

The researchers were happy to discover that all $(100 \%)$ of the respondents felt the game has "fun gameplay" and an overarching "clear purpose". These results meet the design objective for the game to be an entertaining game first and an educational experience second. Furthermore, $83 \%$ of responses recognised that the game could potentially help an individual become a more effective person; supporting the finding on the game having a definitive goal to meet.

The initial prototype of the game (iteration 1) has ultimately been well received, as $100 \%$ of respondents felt excited to play a game of Gr8 Success!. Based on this positive reception, the researchers have identified the SIMS and IMI instruments to make use of to gain much greater insight into the actual impact on motivation as described by SDT. These results will be formally presented in a future work.

\section{VIII.CONCLUSION}

Gr8 Success! is a tabletop serious game intended to have players implicitly learn soft skills such as improved communication skills, more effective organisational skills, enriched teamwork skills, heightened punctuality, superior critical thinking and better social skills (among others).

Gr8 Success! has been a hit thus far. Based on results obtained, the physical design has been finalised on the game cards for iteration 2. The final step before release is to playtest more and balance the various card abilities. This game will be used on NWU Vaal campus in 2019, and will also be rolled out to associated NWU campuses in Potchefstroom and Mahikeng.

\section{ACKNOWLEDGMENT}

The researchers would like to acknowledge SGI-SA for their assistance in developing Gr8 Success! as a new approach and intervention, and the School of Computer Science and Information Systems at the NWU for their willingness to try something new to address the needs of their students directly. 


\section{REFERENCES}

[1] Strauss, V. 2017. The surprising thing Google learned about its employees - and what it means for today's students. Retrieved from goo.gl/dXxbai

[2] Anonymous. 2017. NWU feedback on the draft language policy for higher education. Office of the DVC Teaching and Learning.

[3] SGI-SA. 2017. http://natural-sciences.nwu.ac.za/sgi-sa

[4] Nicholson, S., 2011. Making gameplay matter: Designing modern educational tabletop games. Knowledge Quest, 40(1), p.60.

[5] Benford, S., Magerkurth, C. and Ljungstrand, P., 2005. Bridging the physical and digital in pervasive gaming. Communications of the ACM, 48(3), pp.54-57.

[6] Piper, A.M., O'Brien, E., Morris, M.R. and Winograd, T., 2006, November. SIDES: a cooperative tabletop computer game for social skills development. In Proceedings of the 2006 20th anniversary conference on Computer supported cooperative work (pp. 1-10). ACM.

[7] Magerkurth, C., Cheok, A.D., Mandryk, R.L. and Nilsen, T., 2005. Pervasive games: bringing computer entertainment back to the real world. Computers in Entertainment (CIE), 3(3), pp.4-4.

[8] Xu, Y., Barba, E., Radu, I., Gandy, M. and MacIntyre, B., 2011. Chores Are Fun: Understanding Social Play in Board Games for Digital Tabletop Game Design. In DiGRA Conference.

[9] Evenson, R. 1999. Soft skills, hard sell [Electronic version]. Techniques:Making Education \& Career Connections, 74(3): 29-31.
[10] Bancino, R. \& Zevalkink, C. 2007. Soft skills: The new curriculum for hard-core technical professionals. Techniques: Connecting Educationand Careers (J1), 82(5):20-22.

[11] Deci, E.L. and Ryan, R.M., 2011. Self-determination theory. Handbook of theories of social psychology, 1(2011), pp.416-433.

[12] Reber, A.S., 1989. Implicit learning and tacit knowledge. Journal of experimental psychology: General, 118(3), p.219.

[13] Lewicki, P., Hill, T. and Bizot, E., 1988. Acquisition of procedural knowledge about a pattern of stimuli that cannot be articulated. Cognitive psychology, 20(1), pp.24-37.

[14] McGonigal, J.E., 2011. Reality Is Broken: Why Games Make Us Better and How They Can Change the World. Penguin Press, New York, 1st edition,. ISBN 1-101-46715-0.

[15] Ryan, R.M. and Deci, E.L., 2000. Self-determination theory and the facilitation of intrinsic motivation, social development, and wellbeing. American psychologist, 55(1), p.68.

[16] Krathwohl, D.R., 2002. A revision of Bloom's taxonomy: An overview. Theory into practice, 41(4), pp.212-218

[17] Plomp, T., 2013. Educational design research: An introduction. Educational design research, pp.11-50.

[18] Bunt, L., Leendertz, V. and Blignaut, A.S., 2017, October. A heuristic evaluation of the design and development of a statistics serious game. In Proceedings of the 16th World Conference on Mobile and Contextual Learning (p. 16). ACM.

[19] Van den Akker, J., Gravemeijer, K., McKenney, S. and Nieveen, N. eds., 2006. Educational design research. Routledge.

[20] Covey, S. 1989. The seven habits of highly effective people. New York, Simon and Schuster. 